\title{
Uncertainty estimation to evaluate mass balances on a combustion system
}

\author{
Paula Teixeira • Helena Lopes • Ibrahim Gulyurtlu • \\ Nuno Lapa
}

Received: 28 July 2011/Accepted: 4 February 2012/Published online: 7 March 2012

(C) Springer-Verlag 2012

\begin{abstract}
Mass balances of ash and potassium for a fluidized bed combustor were performed incorporating measurement uncertainties. The total output mass of ash or a chemical element should be equal to the mass in the input fuel; however, this is not often achieved. A realistic estimation of recovery uncertainty can support the reliability of a mass balance. Estimation of uncertainty helps to establish a reliable evaluation of the recovery ratio of ash mass and elemental mass. This may clarify whether any apparent lack in closing the mass balance can be attributed to uncertainties. The evaluation of measurement uncertainty for different matrices, namely coal, biomass, sand and ashes from different streams was based on internal quality control data and external quality control data, namely analysis of samples from proficiency tests or use of a certified reference material. The evaluation of intermediate precision and trueness allowed the estimation of measurement uncertainty. Due to the different physic and chemical characteristics of the studied matrices, the uncertainty of precision was evaluated using R-charts of data obtained from the analysis of duplicates for the majority of samples. This allowed evaluating sample heterogeneity effects. The instrumental acceptance criterion was also considered and included in the combined
\end{abstract}

Presented at the Eurachem/CITAC Workshop on Measurement Uncertainty, June 2011, Lisbon, Portugal.

P. Teixeira $(\bowtie) \cdot$ H. Lopes $\cdot$ I. Gulyurtlu

LNEG, Estrada do Paço do Lumiar, 22, Ed. J,

1649-038 Lisbon, Portugal

e-mail: paula.teixeira@lneg.pt

N. Lapa

UNL-FCT-DCTB-UBiA, Quinta da Torre,

2829-516 Caparica, Portugal uncertainty. The trueness was evaluated using data from several proficiency tests and from analysis of a certified reference material or sample spiking. Statistically significant bias was included.

Keywords Uncertainty budget · Precision - Trueness · Mass balance

\section{Introduction}

As ISO 17025 [1] requires accredited laboratories to estimate the measurement uncertainty, a growing interest on evaluating uncertainties has been observed. This is evident from the increasing number of scientific papers and reports published in this field during the last decade. In literature, different approaches may be found to estimate the uncertainties. Some of them allow the laboratories to obtain reliably uncertainties without spending too much time and human or economic resources. However, the estimation of uncertainty is still mostly carried out in accredited laboratories and National Metrology Institutes. Research laboratories dedicated to applied sciences, like energy and environment, do not consider uncertainty regularly. It must be stressed that the evaluation of measurement uncertainties helps to assess the reliability of experimental data. For example, measurement uncertainty can be used to validate results in the combustion research area. The uncertainty may contribute to understand the ash behaviour of fuels during combustion, for example, the evaluation of the elemental enrichment in specific ash streams. To study the fate of ash, the recovery uncertainties of ash and element contents must adequately be known. It is important to assess whether the recovery ratios of ashes different from $100 \%$ are related to the uncertainty of measurements, to the 